\title{
ONZE ILHAS OU UMA ILHA E DEZ ILHÉUS? A PRESIDÊNCIA \\ DO STF E SUA INFLUÊNCIA NA ATUAÇÃO DO TRIBUNAL
}

\author{
ELEVEN ISLANDS OR ONE ISLAND AND TEN LITTLE \\ ISLANDS? THE BRAZILIAN SUPREME FEDERAL COURT CHIEF \\ JUSTICE AND ITS INFLUENCE ON THE COURT'S \\ PERFORMANCE
}

RESUMO: Na última década, diversos estudos destacaram os poderes dos ministros do Supremo Tribunal Federal para atuar de forma individual. No presente artigo, argumento que a presidência do Tribunal conta com poderes especiais para atuação individual. Após a descrição de tais poderes, lanço hipóteses que podem explicar suas origens e, além disso, indico possíveis consequências da existência e da utilização dos poderes especiais pela presidência. Concluo com a afirmação de que a ministra que ocupar a presidência conta com enormes poderes especiais em relação aos demais ministros do STF, o que justificaria uma nova agenda de pesquisa.

Palavras-Chave: Supremo Tribunal Federal; Processo decisório; Desenho institucional; Presidente do tribunal; Poderes individuais.

ABSTRACT: In the last decade, some studies have highlighted the powers of the Brazilian Supreme Federal Court (STF) justices to act individually. In this paper, I argue that the Chief Justice of the Court has special powers for acting individually. After describing these powers, I point out hypotheses that can explain their origins and possible consequences of the existence and use of special powers by the Chief Justice. My conclusion is that the Chief Justice has much more powers compared to the other justices of the STF, which would justify a new research agenda.

KEYWORDS: Brazilian Supreme Federal Court; Decision making; Institutional design; Chief Justice; Individual powers.

\footnotetext{
${ }^{1}$ Doutorando em Direito do Estado na Universidade de São Paulo (USP). Mestre em Direito pela Universidade do Estado do Rio de Janeiro (UERJ). Professor do Cefet-RJ - Campus Valença. Agradeço a Amanda Melillo, Daniel Capecchi Nunes, Diego Werneck Arguelhes e Gabriela Gattulli pela troca de ideias e pelos comentários a uma versão anterior deste texto. Contato: luizfgesteves@gmail.com.
} 


\section{INTRODUÇÃO}

No final do mês de maio de 2019, o ministro Dias Toffoli, presidente do STF se reuniu com os presidentes da República, da Câmara e do Senado e com eles fechou um pacto pela aprovação das reformas propostas pelo governo (ROSA, 2019). Dias depois, em sinalização ao governo, o presidente do Tribunal retirou da pauta de julgamentos o caso que discutia a descriminalização da posse de drogas para uso próprio (BRÍGIDO, 2019). Meses antes, em outubro de 2018, o mesmo Dias Toffoli cassou a decisão monocrática de seu colega Ricardo Lewandowski que havia autorizado o ex-presidente Lula a conceder entrevistas de dentro do presídio (COELHO, 2019).

Os casos indicam uma intensa participação do presidente do STF na política em um curto espaço de tempo, de pouco mais de seis meses, sem que haja um respaldo expresso do plenário do Tribunal por ele representado, uma atuação individual, portanto. Nos últimos anos, a academia destacou o papel central do individualismo dos ministros na atuação do STF. Analogias não faltaram, o arranjo foi chamado de "as 11 ilhas" "2, de ministrocracia (ARGUELHES, 2018), onze supremos (FALCÃO; ARGUELHES; RECONDO, 2017) ou de tribunal de solistas (MENDES, 2012).

Nessas análises, normalmente são escolhidos certos recursos institucionais, como decisões monocráticas (HARTMANN; FERREIRA, 2016), pedidos de vista (ARGUELHES; HARTMANN, 2017), poderes dos relatores (SILVA, 2016) ou votos monológicos (SILVA, 2015; VOJVODIC; MACHADO; CARDOSO, 2009; MENDES, 2015 , p. 167-168), para indicar os mecanismos que os ministros possuem para a atuação individual ${ }^{3}$. Implicitamente, tais estudos parecem reconhecer que todos os ministros possuem os mesmos instrumentos institucionais ${ }^{4}$, e a variação no uso estaria relacionada com a personalidade do ministro ou sua devoção à colegialidade, já que os mecanismos institucionais permaneceriam os mesmos.

Contudo, algo parece se perder nesse tipo de observação. O presidente do STF,

\footnotetext{
2 A expressão foi criada pelo ministro Sepúlveda Pertence, como ele próprio assume em entrevista ao projeto História Oral do Supremo, da Fundação Getulio Vargas. Cf. Fontainha, Silva e Nuñez (2015, p. 116): “Cheguei a dizer - o ministro Jobim gosta muito de repetir esta frase minha - que éramos onze ilhas incomunicáveis, um arquipélago de onze ilhas incomunicáveis. Realmente, na maior parte dos dezoito anos que passei, as relações pessoais eram extremamente raras. Acontecia de em certos acontecimentos sociais se encontrarem vários ministros, e aí o senso corporativo funcionava muito para que ficassem todos reunidos. Eu sempre fui rebelde a isso. Mas a convivência pessoal era raríssima."

${ }^{3}$ Para uma discussão sobre o uso de alguns desses mecanismos a partir de uma outra perspectiva, a dos diálogos institucionais, cf. Mendes (2011, p. 222-224). O autor destaca que a definição da pauta de julgamento, o voto-vista e a liminares monocráticas são mecanismos não legítimos utilizados pelos ministros do STF para evitar uma decisão.

${ }^{4}$ Mesmo Arguelhes e Ribeiro (2018, p. 18ss), que reconhecem poderes diferenciados do presidente do STF e dos ministros relatores, a partir de diferentes formas de alocação de poderes em um tribunal, não se dedicaram a analisar exclusivamente o papel da presidência e os seus poderes específicos.
} 
como ficou notável nas situações narradas no início da introdução, parece possuir um conjunto adicional de recursos para atuação individual no processo decisório do tribunal ou, no mínimo, para a atuação direta no jogo político. Se o argumento estiver correto, a analogia que melhor descreveria o tribunal não seria a de um arquipélago de onze ilhas, mas sim de um arranjo com uma ilha e dez ilhéus ${ }^{5}$.

O objetivo central do ensaio é descrever quais são os poderes do presidente do STF. A partir daí tentarei entender como tais poderes são atribuídos ao presidente, e quais são as possíveis consequências da utilização de tais poderes. Essa trajetória se reflete na organização do trabalho. No primeiro tópico, indicarei os principais poderes do presidente do STF. No segundo analisarei quais são as fontes de tais poderes, isto é, se decorrem da legislação, de delegação dos pares ou de autoatribuição. Na terceira parte, as consequências do conjunto adicional de recursos do presidente serão discutidas. Em último lugar, a conclusão reunirá os principais achados do trabalho.

Antes de começar, no entanto, um breve esclarecimento é necessário. $\mathrm{O}$ artigo lida com diversos mecanismos institucionais que podem ser utilizados pela presidência do STF, e ainda lança mão de hipóteses que podem explicar a existência de tais poderes e as consequências de seu uso, portanto, o objeto é amplíssimo. Diante disso, a escolha deliberada foi a de fornecer uma imagem geral, ainda que impressionista, no lugar de escolher apenas um aspecto do leque de poderes da presidência para uma análise profunda e detalhada. A decisão se justifica em razão do objetivo central do texto, que é descrever os poderes da presidência que tornam a ministra que ocupe a cadeira uma agente diferente dos demais ministros do tribunal.

\section{QUAIS SÃO OS PRINCIPAIS PODERES DA PRESIDÊNCIA DO STF?}

Na tipologia de Arguelhes e Ribeiro (2018, p. 16-18), o desenho institucional de um tribunal conta com diferentes instrumentos para o exercício de três poderes: decidir, sinalizar e definir agenda. O primeiro, e mais lógico, seria o de decidir, impactando diretamente a política, no caso de um veto à decisão legislativa ou do governo, ou indiretamente, tendo em vista que as decisões passadas do tribunal criam expectativas nos atores que participam do processo político. Se as expectativas criadas por decisões passadas são importantes para a definição do comportamento dos políticos, também importante é a ameaça de uma decisão futura, o que se inclui no segundo poder, o de sinalizar. Por fim, o último poder de um tribunal seria o de definir a agenda, que lidaria com a escolha do momento em

\footnotetext{
${ }^{5}$ Uma exceção digna de nota é o artigo publicado recentemente por José Mário Wanderley Gomes Neto e Flávia Danielle Santiago Lima (2018), em que apresentam argumento semelhante ao que defendo, de que o presidente conta com superpoderes. Contudo, os autores limitaram o campo de análise ao poder do presidente do STF de atuação durante o recesso judicial e férias, o que, na análise que apresento, é apenas um dos poderes especiais do presidente.
} 
que um caso seria julgado.

Por sua vez, para os mesmos autores, esses poderes poderiam ser alocados também de formas diversas em um tribunal. Na primeira espécie, a alocação seria coletiva, e o exercício do poder dependeria da constituição de uma maioria. No segundo caso, a alocação seria individual centralizada, ou seja, o poder seria exercido por um ministro que ocupasse uma posição institucional específica, como a presidência do tribunal ou a relatoria de um caso. Por fim, seria possível a alocação individual descentralizada, sem que o exercício do poder tivesse ligação com uma posição institucional específica (ARGUELHES; RIBEIRO, 2018, p. 18-20). Portanto, na classificação dos autores, o problema por mim enfrentado no presente artigo se enquadra na alocação do tipo individual centralizada, já que tem a ver com a posição institucional específica da presidência do STF.

O Regimento Interno do Supremo Tribunal Federal (RISTF) dedicou três artigos para tratar do presidente e do vice-presidente. No Art. 12, o primeiro dos três, estabeleceu que o mandato do presidente e do vice são de dois anos, vedada a reeleição, e dispôs sobre as regras aplicáveis à eleição. Apesar de dispor sobre eleições, a partir de regras que estabelecem o voto secreto, o quórum mínimo para a realização da eleição, e também o mínimo de votos que um candidato deverá receber para ser considerado eleito, há no STF uma prática sedimentada de escolha automática do presidente.

Por meio da prática, é escolhido como presidente a ministra que tem mais tempo de casa, desde que não tenha ocupado o cargo previamente. No dia designado para a eleição, os ministros se reúnem e dez deles manifestam o voto no ministro que se encaixa neste critério. $O$ único voto que não vai para o eleito é o seu próprio, que se dirige para o segundo ministro mais antigo no tribunal que também não tenha ainda ocupado o cargo de presidente, e tal ministro passa a ocupar a vicepresidência ${ }^{6}$.

No Art. 14, por sua vez, há apenas a regra de praxe de que o vice-presidente substituirá o presidente nos casos de licenças, ausências e impedimentos eventuais. Foi o Art. 13, portanto, o responsável por indicar as atribuições do presidente, e o dispositivo o fez através de seus dezenove incisos. O objetivo do ensaio, no entanto, não é uma mera análise do texto do regimento, mas sim a descrição dos poderes do

\footnotetext{
${ }^{6}$ A prática é tão sedimentada que, recentemente, o ministro Luiz Fux declarou publicamente que seria o próximo ministro do STF, mais de um ano antes da efetiva "eleição". Cf. Coelho (2019). É interessante que, em seus primórdios, já havia disputa sobre as regras que seriam aplicáveis às eleições, sobretudo porque as disposições poderiam funcionar como um reforço da independência do tribunal em relação ao Executivo. Emília Viotti da Costa (2006, p. 33) narra, por exemplo, que no início do funcionamento do STF, presidente e vice deveriam prestar juramento perante o chefe do Poder Executivo, e Floriano Peixoto adiava indefinidamente o ato, o que levava um impasse. Por causa disso, os ministros decidiram reformar o regimento interno, para estabelecer que o juramento deveria ocorrer perante o tribunal. Além disso, também definiram que o PGR seria nomeado pelo tribunal, e não mais pelo chefe do Executivo. As duas medidas aumentaram a independência do STF em relação ao Executivo.
} 
presidente com certa relevância político-institucional, de modo que o RISTF será utilizado principalmente para verificar se a utilização prática de dado poder corresponde à previsão textual. A seguir, analisarei os seis principais poderes presidenciais:

\section{i) Poder de representação;}

Como decorrência lógica do cargo, cabe ao presidente do STF representar o tribunal perante os demais poderes e autoridades. Tal poder, na classificação de Arguelhes e Ribeiro, exposta linhas acima, se enquadra no poder de um tribunal sinalizar preferências. A atribuição desse poder de representação, inclusive, consta expressamente no Art. 13, II, RISTF7. Menos claro, no entanto, é o que essa representação envolve.

Parece fora de dúvidas que a representação do tribunal envolve o encontro com o Presidente da República e reuniões com parlamentares, sobretudo em eventos oficiais $^{8}$, como a cerimônia de posse de chefe de algum dos poderes (SEM AUTOR, 2019a). Mas configuraria representação do tribunal o encontro com atores políticos diversos fora da agenda presidencial, como foi o caso do encontro do então presidente do Supremo, ministro Ricardo Lewandowski, com a presidente Dilma Rousseff em Portugal, ocasião em que os temas discutidos teriam sido a Operação Lava-Jato e um reajuste salarial para os ministros do tribunal? (CAMAROTTI, 2019). Aqui, a dúvida é sobre o tipo de reunião na qual a representação poderá ocorrer.

Além disso, existem dúvidas sobre quais são assuntos em que o presidente do STF representa o tribunal. Um encontro com as demais autoridades para buscar melhorias estruturais para a sede do tribunal, ou para pleitear o aumento dos vencimentos dos ministros, parece se enquadrar na representação do tribunal, enquanto instituição, já que esses fatores podem afetar diretamente o funcionamento do STF ou mesmo sua independência. Porém, seria possível chegar à mesma conclusão se a representação envolvesse um pacto com os demais poderes para a busca da aprovação rápida de uma medida governamental que tivesse por objetivo sanar as contas do país?

Um exemplo recente desse último caso foi a reunião em que os chefes de todos os poderes se comprometeram a unir esforços em torno da aprovação da Reforma da Previdência (ROSA, 2019b?), mas a existência de pactos entre os poderes, envolvendo a presidência do Supremo, não é recente (ARGUELHES; RECONDO, 2019). Isso envolveria a instituição $S T F$, ou, em última medida, se restringiria a

\footnotetext{
${ }^{7}$ Art. 13. São atribuiç,ôes do Presidente:

II - representá-lo perante os demais poderes e autoridades;

${ }^{8}$ Mesmo nesses casos, é importante dizer que não se trata aqui de uma interação que ocorre com os interlocutores que participam de uma deliberação em uma Corte. Para escolhas de desenhos quem levam essa interlocução em conta, cf. Mendes (2015, p. 161-164).
} 
aspectos que poderiam ser definidos pelo tribunal? A segunda dúvida, então, é sobre a os assuntos que podem ser representados.

Para além das duas dúvidas, nos últimos anos cada vez mais os ministros do STF têm se manifestado na imprensa ou nas redes sociais sobre os assuntos mais diversos (MENDES, 2018). O fato não é novo, pois manifestações de ministros podem ser encontradas até mesmo durante o regime ditatorial. Contudo, é perceptível que as manifestações atingiram um grau inédito na história brasileira, e poucos são os ministros que evitam um contato próximo com quaisquer veículos

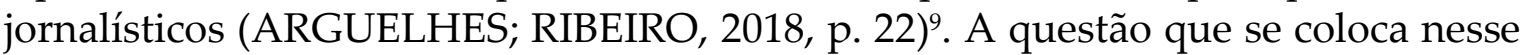
ponto é se as manifestações do ministro presidente do STF podem ser tidas como representação do tribunal ${ }^{10}$.

Ao se manifestar na Universidade de São Paulo, dizendo que acha mais adequado utilizar o termo "movimento" para se referir à ditadura militar, Dias Toffoli sinaliza que o tribunal assim entende ou se trata de uma leitura histórica pessoal (PESSOA, 2018)? Quando a então presidente Cármen Lúcia, em um ambiente político de apoio popular à Lava-Jato, apoia publicamente o combate à corrupção e o recrudescimento das regras penais, essa é uma manifestação do tribunal como um todo? (LIMA, 2018)

Por fim, uma última discussão possível tem a ver com os órgãos representados. O STF é o órgão de cúpula do Poder Judiciário, mas é apenas um dos órgãos desse poder, e por isso convive com a existência de diversos outros tribunais - superiores, federais e estaduais - que possuem representação própria. Não há na Constituição nenhum desenho que indique uma coordenação entre os órgãos do Judiciário no que toca à representação.

Curiosamente, nos últimos meses esse debate se reacendeu. Após a celebração do pacto pela aprovação da Reforma da Previdência, a Associação dos Juízes Federais criticou duramente o presidente do STF, dando a entender que a ação não representava os juízes federais associados. Por outro lado, a Associação dos Magistrados Brasileiros elogiou a participação da presidência do STF na celebração do "pacto" (GULLINO, 2019; REZENDE, 2019).

Por isso surge a dúvida, o presidente do STF representa apenas o STF ou o Judiciário como um todo?

ii) Poder de elaboração da pauta de julgamentos do plenário;

O segundo poder relevante da presidência do STF é o de formular a pauta de

\footnotetext{
${ }^{9}$ Os autores posicionam as manifestações públicas dos ministros como formas de exercício do poder de sinalização de preferências, e indicam que os custos para manifestações individuais são baixos, o que ocasiona uma alocação individual descentralizada, na classificação descrita no início do tópico.

${ }^{10}$ Após o pacto, o ministro Marco Aurélio se manifestou publicamente contra a atuação de Toffoli, o que pode ser um indício de que Toffoli, no caso específico, não representou a todos os componentes do tribunal. Cf. Campos (2019).
} 
julgamentos do plenário do tribunal (MENDES, 2011; ESTEVES, 2018). Em certa medida, o tema envolve o chamado poder de agenda ${ }^{11}$, estudado de forma mais detida no âmbito da Ciência Política, que pode ser definido como o poder de definir quando e quais questões serão resolvidas (KINGDON, 2014, p. 3).

Neste ponto, o que mais se aproxima de previsão legal de tal poder são os Arts. 13, II, e 128, § $2^{\circ}$, do RISTF, que atribuíram à presidência o poder de, respectivamente, dirigir e presidir os trabalhos nas sessões plenárias, e também o de dar preferência a julgamentos em certos casos. Não há, portanto, atribuição expressa desse poder à presidência em todo e qualquer caso ${ }^{12}$. Na ausência de previsão expressa, durante muito tempo esse poder foi exercido pelo secretáriogeral do tribunal. No entanto, esse panorama parece ter se alterado durante a presidência do ministro Nelson Jobim, que deu início à formação das chamadas pautas temáticas (FALCÃO; OLIVEIRA, 2013).

Pouco a pouco, percebeu-se a importância da formulação da pauta, sobretudo em um contexto em que o STF passou a receber dezenas de milhares de processos anualmente. $\mathrm{O}$ tempo do plenário passou a ser um ativo, na medida em que o número de processos prontos para julgamento em muito ultrapassava o número de processos julgados pelo plenário (VERISSIMO, 2008). Nesse contexto, incluir um processo na pauta de julgamentos é uma escolha sensível, que, além de determinar a agenda do tribunal, pode servir para desenhar sua imagem. E essa escolha, nas palavras de Dimoulis e Lunardi (2012), ocorre por meio de critérios pessoais, imprevisíveis e não explícitos.

Os dois últimos presidentes do Supremo, por exemplo, adotaram estratégias próprias para a elaboração da pauta. A ministra Cármen Lúcia se reunia de forma recorrente com presidentes de tribunais, para discutir temas que seriam comuns a todos eles. Além disso, deu início à prática de divulgação das pautas de julgamento com antecedência mensal (BRASIL, 2017). Dias Toffoli, por sua vez, ampliou para seis meses a antecedência na divulgação dos processos que seriam julgados pelo plenário, e em algumas oportunidades priorizou o julgamento de questões que também estavam colocadas no Congresso, como a criminalização da homofobia (BRÍGIDO, 2019).

Outras práticas institucionais do tribunal, no entanto, podem relativizar a importância desse poder de elaboração da pauta. Todos os ministros possuem, na

\footnotetext{
${ }^{11}$ Na classificação de Arguelhes e Ribeiro (2018, p. 20-21), o poder de elaboração da pauta é um dos mecanismos do poder de um tribunal definir sua agenda. Quanto à alocação, indicam que ela ocorre em níveis individuais distintos, com a participação decisiva do presidente na formulação da pauta, mas com a atribuição de poderes de vetos aos ministros para impedir o julgamento, por meio dos pedidos de vista, além de um poder específico do relator de liberar o caso. Portanto, a definição da agenda não seria exclusiva da presidência do STF. V.

${ }^{12}$ Resende e Vieira (2018) argumentam que o novo Código de Processo Civil, no Art. 934, confere esse poder ao presidente do Tribunal. Além disso, fazem um apanhado histórico das regras aplicáveis à formação da pauta do STF desde 1891.
} 
prática, o poder de decidir sobre as questões de sua relatoria de forma individual, bem como de pedir vistas sobre os casos que tiveram o julgamento iniciado no plenário. Com isso, os ministros podem funcionar como pontos de veto à pauta do plenário designada pelo presidente. No caso das decisões monocráticas, eles podem simplesmente evitar o plenário, proferindo uma decisão e não liberando o processo para o julgamento. No segundo caso, do pedido de vistas, o ministro interrompe a pauta do plenário mesmo após o início do julgamento. Nos dois casos, o ministro traz para si o poder de agenda, já que a definição de "quando" o caso será julgado dependerá, como regra, de sua atuação (ARGUELHES; HARTMANN, 2017).

Contudo, ainda assim o poder de pauta se apresenta como um mecanismo institucional especial nas mãos da presidência do STF. Para destacar sua importância, basta imaginar que no tribunal há um conjunto de diferentes casos prontos para julgamento, e tais casos são divididos entre todos os ministros. Logo, a presidência, com o poder de pauta, possui um mecanismo para punir um ministro individual. Por exemplo, se o ministro A pede vistas para interromper o julgamento de um caso $X$, importante para a presidência do tribunal, essa pode, como retaliação, deixar de pautar o caso $Y$, importante para o ministro A, até que este devolva o processo para julgamento. Com isso quero dizer que a lógica da relação entre um ministro e a presidência deve levar em conta o jogo que envolve todo o acervo do tribunal, e não um caso específico que conte com o pedido de vistas.

A questão é: na ausência de previsão expressa sobre o ator encarregado de elaborar a pauta de julgamentos do plenário, é ideal que o poder seja exercido de forma solitária pelo presidente do tribunal?

\section{iii) Poder de concessão de liminares nos plantões judiciários;}

No momento em que chegam ao STF, os processos são distribuídos a algum de seus ministros, que por sorteio será escolhido o relator do caso. Esse relator ficará encarregado da instrução do feito, e de despachar sobre algumas questões que são apresentadas até que o processo seja efetivamente julgado, como o pedido para a participação de alguma entidade como amicus curiae. Até aqui não há polêmicas. Em boa parte dos processos, no entanto, o autor pede que seja concedida uma medida liminar, dada a urgência do tema que foi submetido ao tribunal. A prática recente do tribunal tem sido a de que, na ausência de previsão legal, os ministros relatores podem decidir sobre esses pedidos de forma individual ${ }^{13}$, e muitas vezes essas decisões demoram anos para serem apreciadas pelo plenário do tribunal.

\footnotetext{
${ }^{13} \mathrm{O}$ poder de concessão de liminares, em geral, é classificado por Arguelhes e Ribeiro (2018, p. 2326) como um poder de tomada de decisão, alocado de forma individual e centralizada nos relatores. Apesar de não tratarem especificamente do poder da presidência de concessão de liminares no recesso, é possível dizer que tal poder também seria classificado como de tomada de decisão, e sua alocação também seria individual e centralizada, desta vez na figura do presidente. Para estatísticas recentes das decisões monocráticas ver Teixeira (2018).
} 
Ao contrário da prática institucional recente, que é exercida na ausência de previsão legal, o RISTF atribui à presidência do tribunal o poder de decidir sobre questões urgentes durante os períodos de recesso e férias ${ }^{14}$. O que preocupa, portanto, não é a falta de autorização legal para agir, mas sim como esse poder pode ser exercido.

Da forma posta, nada impede que o poder seja utilizado como uma forma de burlar o poder do relator - caso se aceite que esse poder é legítimo - ou do plenário do tribunal (OLIVEIRA; D'AGOSTINO, 2019). Um exemplo simbólico da prática ocorreu no último recesso judiciário da presidência da ministra Cármen Lúcia. Em uma ação protocolada no dia 13/7/2018, o Conselho Federal da OAB pedia a suspensão de uma resolução da Agência Nacional de Saúde Suplementar que entraria em vigor dali a seis meses. A ação foi distribuída para a relatoria do ministro Celso de Mello. Contudo, três dias depois, em 16/7/2018, a ministra Cármen Lúcia concedeu a medida cautelar, em meio ao recesso. A decisão foi tomada a despeito da própria Cármen Lúcia ter conhecimento de que Celso de Mello, "o relator natural" do caso, assumiria a presidência de forma interina nos dois dias seguintes, 17 e 18/7/2018, já que Cármen Lúcia precisaria assumir interinamente a presidência da República. Portanto, a presidente do Supremo se antecipou em um dia para decidir sobre a validade de uma lei que apenas entraria em vigor em seis meses, e cujo caso tinha a relatoria de outro ministro (RECONDO, 2015).

Em outro caso, a mesma Cármen Lúcia "perdeu" a relatoria para Ricardo Lewandowski, então presidente do STF. No primeiro dia do recesso de dezembro de 2014, foi ajuizada uma ADI que pedia a suspensão de uma portaria Interministerial que estabelecia a publicidade de um cadastro de empresas que já haviam sido autuadas por submeter pessoas a condições análogas ao trabalho escravo. A ação foi distribuída, por prevenção, para a ministra Cármen Lúcia, pois ela tinha em mesa outra ação que cuidava de tema semelhante. Mesmo assim, Lewandowski decidiu, durante o recesso, suspender a norma questionada, impedindo por meses uma importante política pública de combate ao trabalho escravo (GLEZER; MACHADO, 2015).

Levando em conta que o STF está em férias ou recesso durante mais de dois meses por ano, o que se tem, de fato, é a ampliação da competência do ministro que ocupe a presidência para decidir sobre questões urgentes em todos os processos do tribunal em pelo menos um sexto do seu tempo de funcionamento por ano.

iv) Poder de revisão das decisões individuais dos ministros;

Nos últimos anos, o exercício do poder individual pelos relatores para decidir questões liminares tem colocado o STF em uma posição desconfortável, tanto do ponto de vista político, externamente, quanto do ponto de vista interno, com o

${ }^{14}$ Esse poder específico foi analisado de forma profunda por Gomes Neto e Lima (2018). 
acirramento de conflitos entre ministros por causa do conteúdo das decisões ou mesmo pela forma de proceder. Esses problemas parecem ter dado origem a um novo poder.

Ainda que de forma embrionária, com exercício limitado a pouquíssimos casos, a presidência do STF passou a exercer a função de revisora das liminares monocráticas dos ministros ${ }^{15}$. Apesar de amplamente previsto em diversas leis, como nas leis da ação civil pública, do habeas data, ou do mandato de segurança, ${ }^{16}$ não está claro se o pedido de suspensão de segurança ou de liminar se aplica ao STF, sobretudo nos casos de liminares em ações abstratas de inconstitucionalidade, que possuem legislação própria e não contam com a autorização para tanto.

Várias decisões exemplificam o exercício desse poder nos últimos meses. Durante a corrida presidencial de 2018, entre Jair Bolsonaro e Fernando Haddad, muito se discutia sobre a participação do presidente Lula na corrida eleitoral, já que ele estava preso cumprindo provisoriamente a pena pela prática de corrupção e lavagem de dinheiro. No final de setembro de 2018, o ministro Ricardo Lewandowski decidiu, monocraticamente, que Lula poderia conceder entrevistas da prisão. No mesmo dia, Luiz Fux, que ocupava a presidência de forma interina, suspendeu a decisão de Lewandowski. O ministro Lewandowski insistiu na manutenção da decisão, dois dias depois, mas o presidente titular, Dias Toffoli, referendou a decisão de Luiz Fux, mantendo a suspensão, o que acabou por prevalecer (FALCÃO, 2018).

Apesar do poder ter sido ampliado recentemente, sua utilização já gerou um conflito público entre os ministros Marco Aurélio e Dias Toffoli. O ministro Marco Aurélio foi alvo do poder presidencial em pelo menos três oportunidades diferentes. Na primeira, em dezembro de 2018, Marco Aurélio, na véspera do recesso judicial, decidiu, em liminar monocrática, libertar todos os presos que cumpriam a pena provisoriamente após condenação em segunda instância, em decisão contrária ao que foi decidido pelo plenário do Supremo anos antes. Toffoli agiu rápido, e cassou a decisão no mesmo dia (SEM AUTOR, 2019b).

Também no último dia antes do recesso judicial, o mesmo Marco Aurélio decidiu monocraticamente que a votação para a escolha do próximo presidente do Senado deveria ser realizada de forma aberta. A resposta de Toffoli não foi tão rápida, mas chegou no início de janeiro de 2019, com uma nova cassação da liminar (ESTEVES, 2019).

A última decisão do duelo Marco Aurélio/Toffoli teve início com outra liminar monocrática de Marco Aurélio no último dia de funcionamento do tribunal antes

\footnotetext{
${ }^{15}$ Como os casos a seguir demonstrarão, esse poder individual de cassação de liminares foi exercido apenas pela presidência do Supremo, ainda que por seu ocupante interino. Portanto, na classificação de Arguelhes e Ribeiro, se estaria diante de um poder de tomada de decisão cuja alocação seria individual e centralizada.

${ }^{16}$ Por exemplo: Art. 12, 1ํㅡ, da Lei 7.347/85, Art. 4º da Lei 8.437/92, Art. 16 da Lei 9.407/97, Art. 15 da Lei 12.016/09.
} 
do recesso que teria início antes das festas de final do ano de 2018, e nela se impediu, na prática, que a Petrobrás se desfizesse de ativos sem a realização de licitação. A reação de Toffoli mais uma vez não foi imediata, mas veio no início do ano seguinte, com nova cassação (BRÍGIDO, 2019).

Os casos colocam em evidência a utilização do poder da presidência do Supremo que, se não é novo, viu seu raio de ação ser ampliado em um patamar inédito nos últimos tempos. Além disso, indicam que os poderes especiais da presidência podem ser utilizados estrategicamente de forma cumulativa, eis que, nos últimos dois exemplos, a cassação da decisão foi justificada pelo exercício do poder de concessão de liminares durante o recesso judiciário.

v) Poder de organização das sessões;

Ao tratar do poder de formulação da pauta, eu disse que o RISTF atribuiu à presidência o poder de dirigir e presidir os trabalhos do plenário do tribunal. A princípio, portanto, a presidência pode, por exemplo, conceder a palavra para esclarecer algum ponto de seu requerimento, cassar a palavra de ministros que discutem de forma áspera sobre ponto que não diga respeito ao assunto tratado no processo que se está julgando, etc ${ }^{17}$.

Menos óbvio, no entanto, é o poder que a presidência utiliza para organizar as sessões, algumas vezes, inclusive, em desacordo com o que está estabelecido no RISTF. É importante lembrar, mais uma vez, que o tempo de plenário é um ativo importante, portanto, pode ser valioso contar com poderes para influenciar a possibilidade de produzir ou impedir a utilização desse tempo, e a análise da prática do tribunal é de que a presidência conta com alguns poderes especiais para tanto.

O primeiro poder é o de determinar a realização de sessões extraordinárias, normalmente na manhã que precede a sessão ordinária, às quartas-feiras. Ao fazer isso, a presidência conta com mais espaço para preencher com os processos que deseja ver apreciados pelo tribunal, já que o poder de pauta também parece estar nas mãos da presidência. No primeiro semestre de 2019, por exemplo, foram realizadas sete sessões extraordinárias nas manhãs de quartas-feiras ${ }^{18}$.

\footnotetext{
17 O que chamo de poder de organizar sessões também não foi objeto de análise específica por Arguelhes e Ribeiro. Utilizando a classificação dos autores, no entanto, seria possível afirmar que ele se enquadra no campo definição da agenda. Quanto à alocação, o poder da presidência seria individual e centralizado, contudo, os demais ministros poderiam atuar de forma individual e descentralizada para desorganizar as sessões, por exemplo, por meio da utilização de apartes ou com esclarecimentos sobre seus votos. De todo modo, a presidência ainda assim conservaria os poderes especiais que indico no texto, como, por exemplo, o de determinar o encerramento da sessão, o que entendo não ser desprezível.

${ }^{18}$ Toffoli designou oito sessões extraordinárias para manhãs de quartas-feiras, nos dias 27/2, 13/3, $10 / 4,24 / 4,8 / 5,22 / 5,12 / 6$ e 26/6. No entanto, a sessão do dia 10/4 foi cancelada. É importante esclarecer, além disso, que formalmente as sessões plenárias das quintas-feiras são consideradas extraordinárias. No entanto, a realização dessas sessões é prática consolidada no tribunal, e
} 
Mais sutil que o anterior é o poder de indicar o horário de início, término, e dos intervalos das sessões. Ao manejar os atrasos no início ou no retorno do intervalo ou mesmo na existência ou não de intervalos -, bem como a prorrogação da sessão para além do horário determinado, a presidência traz para si a possibilidade de manejar o tempo como melhor lhe aprouver. Por exemplo, caso tenha interesse no julgamento de um caso, pode começar a sessão no horário determinado e prorrogar o seu encerramento, ou, por outro lado, atrasar seu início e antecipar seu encerramento. Um exemplo recente ocorreu no julgamento da ADI 6121, que questionava a extinção de conselhos e colegiados da Administração Pública por meio de decreto presidencial. No dia 12/6, após 9 votos contra a medida do governo, sendo que 5 deles restringiam de forma mais rígida o poder presidencial, o ministro Toffoli pediu vista dos autos. A devolução ocorreu no dia seguinte, quando o ministro Gilmar Mendes - que estava ausente no dia anterior - estava presente na sessão, e então o placar mudou, com a declaração de inconstitucionalidade em menor extensão. ${ }^{19}$

Por outro lado, caso o interesse seja o não julgamento de um caso, é possível avisar de antemão que naquela sessão será realizada apenas a leitura do relatório e a manifestação de advogados (D'AGOSTINO; BARBIÉRI, 2019) ${ }^{20}$, ou, o que é mais comum, nem é necessário avisar, basta manipular o tempo de modo que não haja tempo suficiente para o julgamento na sessão determinada.

vi) Poder de abertura de inquérito

As eleições presidenciais de 2018 testemunharam um avanço na divulgação de notícias falsas, a ponto de se questionar se era possível a anulação do pleito em um caso extremo de disseminação das chamadas fake news. O aumento na divulgação de notícias falsas não se limitou, no entanto, ao período eleitoral, e nem ficou restrita aos candidatos que disputavam o pleito. O Supremo supostamente se tornou um alvo de ameaças e fake news.

Uma dessas possíveis ameaças ou fake news teria sido a divulgação de matérias que ligavam o presidente do Supremo, ministro Dias Toffoli, a empreiteiras que estavam envolvidas em diversos escândalos de corrupção ${ }^{21}$.

ninguém cogita de realização de sessões plenárias apenas às quartas, por isso as informações levaram em conta as sessões extraordinárias que ocorreram apenas nos horários incomuns.

${ }^{19}$ Ver Freitas (2019). O julgamento do mensalão também é um exemplo emblemático do exercício de tal poder. No momento em que o tribunal decidia sobre o cabimento dos embargos infringentes, o então presidente Joaquim Barbosa, contrário ao cabimento do recurso, interrompeu a sessão de julgamento em uma quinta-feira, impedindo o voto de desempate do ministro Celso de Mello, que desejava votar naquela oportunidade, para pressionar o ministro a votar de forma contrária ao cabimento dos recursos, já que durante todo o final de semana, a imprensa - e mesmo um ministro do STF - o pressionaria para que assim votasse. O caso é narrado por Recondo e Weber (2019, p. 202-203).

${ }^{20}$ Como ocorreu, por exemplo, no início do julgamento sobre a criminalização da homofobia.

${ }^{21}$ Para um resumo do caso ver Diniz (2019). 
Nesse contexto, a presidência do tribunal viu que havia um dever - ou uma oportunidade - de agir. Interpretando o RISTF 22 , determinou a abertura de inquérito, que deveria ser processado no âmbito do próprio Supremo, para apurar as supostas ameaças e fake news dirigidas ao tribunal. Na ocasião, além de determinar a abertura do procedimento, o presidente Dias Toffoli atribuiu a relatoria ao ministro Alexandre de Moraes, sem a realização de qualquer sorteio prévio. Uma das primeiras medidas tomadas pelo relator do inquérito foi a suspensão da divulgação das matérias contrárias ao presidente do tribunal.

É verdade que esse poder só foi utilizado em uma oportunidade e sequer há decisão judicial sobre sua existência ou limites. Além disso, o seu exercício gerou diversas críticas por parte da comunidade jurídica e dos próprios ministros do Supremo ${ }^{23}$, e por isso é cedo para dizer que, assim como nos demais poderes, há uma prática consolidada. Todavia, ainda assim, trata-se de um poder especial, pois não está à disposição de outros ministros. O que fica pendente é se será ou não confirmado judicialmente e, mais do que isso, se será utilizado de forma recorrente pela presidência do tribunal.

\section{QUAIS SÃO AS FONTES DOS PODERES DA PRESIDÊNCIA?}

No tópico anterior foram analisados os principais poderes que a presidência detém para, de forma individual, decidir o futuro de casos ou, ao menos, alterar a percepção do público sobre o Supremo, como ocorre nos casos de manifestações públicas na imprensa. Cabe agora discutir de onde esses poderes vêm. As hipóteses giram em torno de três possíveis explicações. Os poderes podem ter origem na legislação, na delegação dos demais ministros ou na autoatribuição por parte da presidência.

Antes de explorar cada uma das fontes, no entanto, é necessário um breve esclarecimento. É possível analisar as fontes de cada um dos poderes a partir de diferentes perspectivas. Em uma primeira perspectiva, a fonte pode ser lida como $o$ ato que cria abstratamente um poder. De outro ponto de vista, a fonte pode dizer respeito à forma de exercício de um poder que, apesar de previsto abstratamente, é interpretado para situações que não estão compreendidas de forma expressa nos limites do texto. Por último, seria possível cogitar da fonte de legitimidade da criação de um poder ou de seu exercício, que geraria uma análise sobre sua correção ou não. As duas primeiras fontes podem ser utilizadas para descrever os poderes da presidência, no sentido por mim abordado. Contudo, na terceira perspectiva, a

\footnotetext{
22 Art. 43. Ocorrendo infração à lei penal na sede ou dependencia do Tribunal, o Presidente instaurará inquérito, se envolver autoridade ou pessoa sujeita à sua jurisdição, ou delegará esta atribuição a outro Ministro. $\S 1^{\circ}$ Nos demais casos, o Presidente poderá proceder na forma deste artigo ou requisitar a instauração de inquérito à autoridade competente. $\S 2^{\circ} \mathrm{O}$ Ministro incumbido do inquérito designará escrivão dentre os servidores do Tribunal.

${ }^{23}$ Por exemplo, cf. Grillo (2019).
} 
análise se deslocaria para um debate normativo, sobre a legitimidade ou não de dado poder da presidência ou de seu exercício, e considerações desse tipo claramente estão fora do escopo do trabalho.

Feito o esclarecimento, a primeira fonte de criação dos poderes presidenciais é a legislação, isto é, como agentes públicos que são, os ministros que ocupam a presidência do STF devem checar quais são os seus poderes na Constituição, nas leis e no RISTF, pois a legislação é, sobretudo para os agentes públicos não eleitos, a primeira fonte de criação de competências.

Dentre os seis poderes analisados, quatro decorrem claramente da legislação: o de representação, o de concessão de liminares nos plantões judiciários, o de organização das sessões e o de abertura de inquérito. Todavia, mesmo nesses casos, foram apontadas situações em que o efetivo exercício de tais poderes parece ter transbordado os limites semânticos ou a finalidade da previsão legal. A representação perante os demais poderes, na prática, tem ocorrido não apenas perante poderes, mas também perante a imprensa, de forma recorrente, e, além disso, não está claro que o tribunal é representado institucionalmente em todas as manifestações de sua presidência. A concessão de liminares durante os plantões pode, em alguns casos, ser utilizada não como modo de suprir uma urgência, mas sim como forma de superar a atribuição formal da relatoria a um determinado ministro. Por sua vez, a organização das sessões tem ido muito além do que o controle dos trabalhos, com o estabelecimento de expedientes que geram consequências diretas nos resultados dos processos. Já que nessas situações a fonte não parece ser a legislação, é necessário buscar hipóteses alternativas. Em último lugar, a abertura de inquérito foi utilizada para apurar situações que claramente não se encontravam nos limites semânticos do texto.

Ao menos no caso das previsões regimentais, é possível cogitar que os demais ministros delegaram previamente um poder à presidência, e que por isso a regra foi criada. Mas em outros casos, como dito, a regra não existe, ou não é explícita para certas situações. A segunda hipótese é a de que a criação ou o exercício dos poderes diferenciados da presidência decorre de delegação dos demais ministros ${ }^{24}$. A presidência teria, por exemplo, o poder de se reunir para apoiar uma reforma do governo ou de elaborar a pauta de julgamentos por ter recebido uma autorização, implícita ou explícita, dos outros ministros do tribunal.

Essa hipótese é de difícil comprovação empírica, pois sugere que o silêncio dos demais ministros, em certos casos, pode configurar delegação. Contudo, alguns indícios da existência de certa delegação podem ser inferidos de situações opostas ao silêncio delegatório, isto é, de manifestações de ministros que digam

\footnotetext{
${ }^{24}$ Danilo dos Santos Almeida e Andre Martins Bogossian (2016; 2018), em artigos que dialogaram com textos de Virgílio Afonso da Silva, formularam a tese do delegacionismo no STF em outro aspecto, o de que os demais ministros delegariam ao relator o papel de indicar a fundamentação que serviu de base para o acórdão. Apesar de discordar das conclusões dos autores, o argumento se aplica aqui.
} 
expressamente que não concordam com determinado poder exercido pela presidência. Isso ocorreu em alguns casos recentes, em que um ministro publicamente discordou da extensão dos poderes da presidência para representar o STF (CAMPOS, 2019), para elaborar a pauta de julgamentos (O GLOBO, 2018) ou mesmo para organizar sessões com o início atrasado (VALENTE, 2018; CANÁRIO, 2015). Mesmo nesses três exemplos, todavia, não é possível afirmar peremptoriamente que não houve delegação, sobretudo se for considerado que as três manifestações foram de ministros individuais, e não da maioria do tribunal, $\mathrm{o}$ que torna ainda mais evidente a dificuldade de submeter a hipótese a testes empíricos.

Outra hipótese é a de que os poderes da presidência podem ter como fonte a autoatribuição do titular do cargo. Como dito por Arguelhes, "O Supremo é o principal intérprete de seus próprios poderes - e, ao lê-los, vem sendo bastante generoso consigo mesmo" (ARGUELHES, 2019). A lógica se aplica também para a presidência. Neste caso, o eventual ocupante da presidência tateia os limites de sua função, e busca expandi-los quando visualiza uma oportunidade ${ }^{25}$, criando ou alargando um poder ${ }^{26}$. Essa hipótese parece explicar pelo menos dois dos poderes da presidência: o de elaborar a pauta de julgamentos e o de revisão das decisões individuais dos ministros.

No caso do poder de pauta, a origem é a presidência do ministro Nelson Jobim (FALCÃO; OLIVEIRA, 2013), quando ele então passou a elaborar as pautas temáticas (FONTAINHA et al., 2015). Esse poder se desenvolveu ao longo dos anos, e, como visto, durante a presidência da ministra Cármen Lúcia, uma nova prática parece ter sido criada, a de antecipação mensal do calendário de julgamentos (ESTEVES, 2018, p. 87-94), o que foi expandido pelo ministro Dias Toffoli, que passou a divulgar o calendário com antecipação semestral (BRASIL, 2018). Todas essas circunstâncias parecem ter decorrido de projetos pessoais dos eventuais ocupantes do cargo, e não de um projeto institucional do STF, por meio de deliberação e delegação dos demais ministros, daí a hipótese de autoatribuição.

Já no caso de revisão de decisões dos ministros, a prática parece ter uma origem recente, com revogações de decisões na presidência do ministro Dias Toffoli. Isso ocorreu em pelo menos três oportunidades. Contra decisão do ministro Lewandowski que havia autorizado entrevista do ex-presidente Lula (COELHO, 2018), e contra o ministro Marco Aurélio, uma vez contra decisão que havia revogado a prisão de todos aqueles que cumpriam a pena provisoriamente após decisão em segunda instância (SEM AUTOR, 2019b), na segunda vez ao derrubar a

\footnotetext{
${ }^{25}$ Em artigo de opinião, Thomaz Pereira (2017) chamou atenção para o problema que a atuação individual dos ministros pode causar ao tribunal. Em suas palavras: "Ao atuarem individualmente, os ministros se beneficiam sozinhos da autoridade coletiva do tribunal - e a erodem".

${ }^{26}$ Para um breve apanhado das teorias que buscaram explicar o comportamento dos juízes, ver Hilbink (2007, p. 23-27).
} 
decisão que havia determinado a eleição aberta para a escolha do próximo presidente do Senado (OLIVEIRA; D'AGOSTINO, 2019) e, por último, contra decisão do mesmo ministro que dificultava a venda dos ativos da Petrobrás (RESENDE, 2019).

As duas últimas hipóteses são de difícil comprovação empírica e, além disso, podem se alimentar ou excluir mutuamente. Nada impede, por exemplo, que um poder seja criado por autoatribuição do ocupante do cargo, mas que sua manutenção ocorra por meio de uma delegação implícita, por exemplo. Em outros casos, o que foi apontado aqui como autoatribuição pode ter sido fruto de um poder costurado junto aos demais ministros, o que se encaixaria na hipótese de delegação.

\section{QUAIS SÃO AS CONSEQUÊNCIAS DOS PODERES ESPECIAIS DA PRESIDÊNCIA?}

A princípio, a concentração de poderes especiais na presidência de um tribunal não é um problema em si. Nos Estados Unidos, por exemplo, por vezes a identificação do presidente com o tribunal que representa é tão grande que os períodos em que a presidência se deu são identificados com o próprio nome do titular do cargo, por exemplo, a "Corte Warren", durante a presidência do chief justice Earl Warren, notabilizada pela expansão dos direitos civis. Contudo, é necessário deixar claro que os arranjos institucionais trazem consigo diversas consequências, que podem ser boas ou ruins, e este é precisamente o ponto que pretendo discutir nos próximos parágrafos.

A primeira consequência é a criação de poder excepcional da presidência evitar derrotas pessoais. Isso decorre da união de diversos aspectos institucionais. No STF, a votação ocorre a partir de uma ordem predeterminada, em que o relator é o primeiro a votar e daí se segue uma votação na ordem contrária à antiguidade no tribunal, ou seja, os mais novos no tribunal votam primeiro, e os mais antigos por último ${ }^{27}$. Contudo, o voto derradeiro é o do presidente do STF. Como também possui o poder de organizar as sessões e de elaborar a pauta, a presidência tem diversos mecanismos para evitar a derrota. Por exemplo, ao notar que um caso se encaminha para um resultado contrário ao desejado, o presidente pode encerrar a sessão de forma precoce, ou, ao notar que um caso já possui maioria em um sentido contrário ao seu, o presidente pode simplesmente não mais colocar o caso na pauta, ou pode encaixá-lo nas últimas posições das pautas diárias, sabendo que há pouquíssima chance do tempo viabilizar a discussão do caso $^{28}$. Essa primeira consequência, portanto, produz principalmente efeitos internos ao tribunal, no sentido da relação entre ministros e a presidência.

\footnotetext{
27 Sobre a desigualdade produzida pela ordem pré-estabelecida de votação, ver Silva (2013, p. 571572) e Leflar (1983, p. 726) .

${ }^{28}$ Isso quase ocorreu no exemplo já comentado da discussão sobre o decreto presidencial que extinguiu os conselhos e colegiados no nível da Administração Pública Federal.
} 
A segunda consequência tem relação com os outros poderes. O sistema político brasileiro é caracterizado como um presidencialismo de coalizão, pois, para avançar reformas, o Presidente da República necessita criar maiorias consistentes na Câmara e no Senado, o que se dificulta diante da grande fragmentação interna nos órgãos legislativos. Porém, além dessa dificuldade inicial imposta ao Executivo, nada impede que a oposição busque o STF para que as decisões do governo sejam revertidas judicialmente. Os mecanismos de acesso ao tribunal são relativamente fáceis de serem preenchidos, o que faz com que quase todos os temas importantes ao governo sejam levados ao Judiciário (VIEIRA, 2008), e a grande dificuldade passa a ser, em verdade, fazer com que o caso seja julgado, diante do grande acervo do STF.

Nesse contexto, o apoio da presidência do STF é um grande ativo, pois o ocupante do cargo terá poderes especiais para colocar um assunto na pauta de julgamentos do plenário ou mesmo de decidir individualmente um caso que sequer está sob sua relatoria. A presidência poderá funcionar como geradora solo de crises para o governo, caso não esteja a ele alinhada, ou como impulsionadora da agenda do Executivo. Em todo caso, por causa dos poderes especiais da presidência do STF, ela passa a ser um elemento indispensável para a coalizão presidencial (NUNES; ESTEVES, 2019), o que pode causar uma irritação no princípio da separação de poderes.

O presidente da República parece ter se atentado para esse fato. Ao defender a indicação de um ministro "terrivelmente evangélico" para o tribunal, Jair Bolsonaro exemplificou a importância da nomeação indicando que ele poderia "sentar em cima" do processo que definiria a criminalização da homofobia, impedindo assim a deliberação sobre o caso, provavelmente com um pedido de vistas (PEREIRA; ARGUELHES, 2019). Além disso, o mesmo Bolsonaro acenou para Toffoli em diversas oportunidades, e em uma delas, se referindo ao presidente do STF, disse expressamente: "É muito bom nós termos aqui a Justiça ao nosso lado" (MAIA; SOARES, 2019). A importância da presidência do STF para o chefe do Executivo, portanto, não parece mera especulação.

A terceira consequência possui ligação com a anterior, e representa a ampliação do risco de captura do ministro que ocupe a presidência. O risco da captura dos ministros foi apontado por Arguelhes e Ribeiro em artigo que discutia os poderes individuais dos ministros do STF (ARGUELHES; RIBEIRO, 2018, p. 30), em que se dizia que a alocação individual e descentralizada de poderes facilitava a captura dos ministros, que se portariam como instituições independentes. $\mathrm{O}$ meu argumento é o de que os presidentes possuem ainda mais poderes que os ministros comuns, e, por isso, seriam os alvos principais de captura pelos grupos de interesse, aqui entendidos em sentido geral, para abarcar inclusive o governo. Por isso, a independência judicial correria ainda mais riscos, já que, pelo fato da presidência contar com poderes especiais, o alvo principal seria aquele cuja atuação individual indevida poderia trazer maiores prejuízos à autonomia da instituição STF. 
O arranjo de concentração de poderes especiais na presidência do STF, portanto, pode gerar consequências ruins de pelo menos três ordens. Na primeira, cria incentivos para que decisões sejam evitadas, na segunda é um problema de separação de poderes, e na última torna a independência judicial ainda mais frágil do que na estrutura de atribuição de poderes individuais para os ministros.

\section{CONCLUSÃo}

O objetivo principal do ensaio foi discutir a natureza, as fontes e as consequências dos poderes especiais da presidência do STF. $O$ argumento que permeou todo o trabalho foi o de que os poderes individuais do ministro que ocupa o cargo de presidente do tribunal são ainda mais destacados do que os dos demais ministros, o que justificaria um novo flanco na agenda de pesquisa que analisa o comportamento individual dos ministros do STF.

Se o argumento de base se sustentar, um conjunto de questões de pesquisa surge naturalmente. A primeira seria sobre a posição ocupada pela presidência do tribunal. Estudos semelhantes foram conduzidos para analisar a natureza da presidência de órgãos legislativos, em duas perspectivas diferentes. Uma quanto à posição do presidente sobre os demais ministros - se é um entre ou sobre os colegas. Ou quanto ao conjunto de poderes - se é representante do STF, se é líder da maioria, se é líder da minoria ou um líder neutro (JENNY; MÜLLER, 1995, p. 326-364; ESTEVES, 2018, p. 85ss).

Diversos trabalhos também poderiam analisar de forma específica cada um dos poderes especiais da presidência, a exemplo do que já foi realizado em recente estudo sobre o poder de concessão de medidas cautelares pela presidência durante o recesso forense ou as férias (GOMES NETO; LIMA, 2018).

Além disso, as hipóteses sobre a fonte dos poderes presidenciais poderiam ser testadas empiricamente, por meio de entrevistas ou a partir da análise de dados quantitativos que mapeassem a construção da pauta do tribunal, por exemplo. Outras pesquisas poderiam discutir possíveis soluções para os problemas que decorrem do arranjo institucional da presidência do tribunal ${ }^{29}$. Por exemplo, a alteração da prática institucional de eleições automáticas, em que quase todos os ministros ocuparão a cadeira de presidente, contribuiria para diminuir o impacto dos poderes individuais ou não? Em que medida a clareza na elaboração e no funcionamento da pauta reduziria o risco de captura? Etc.

De todo modo, o que parece fora de dúvidas é que, se mantida a figura do STF como um arquipélago, a presidência não é uma ilha qualquer. É uma ilha maior do que as outras, que aqui chamei de ilhéus, não para dizer que as pequenas ilhas têm

\footnotetext{
${ }^{29}$ Tudo isso levando em conta que o desenho institucional pode funcionar como um facilitador da capacidade deliberativa da Corte. Todas as práticas aqui mencionadas, a princípio, são exercidas de forma individual e antideliberativa pela presidência do STF. Sobre o ponto, ver Mendes (2015, p. 145-149).
} 
poderes diminutos ou menores do que os já apontados pelos analistas, e sim para destacar que a presidência conta com enormes poderes especiais.

\section{REFERÊNCIAS}

ALMEIDA, Danilo dos Santos; BOGOSSIAN, Andre Martins. "Nos termos do voto do relator": considerações acerca da fundamentação coletiva nos acórdãos do STF. Revista Estudos Institucionais, v. 2, n. 1, p. 264-297, 2016.

ALMEIDA, Danilo Dos Santos; BOGOSSIAN, Andre Martins. O delegacionismo no STF: uma tréplica a Virgílio Afonso da Silva. REI - REVISTA ESTUDOS INSTITUCIONAIS, v. 3, n. 2, p. 1393-1422, 2018.

ARGUELHES, Diego Werneck. Reforma do Supremo Individual: resistência dos ministros não fará a pauta sumir. In: FALCÃO, Joaquim; ARGUELHES, Diego Werneck; PEREIRA, Thomaz; et al (Orgs.). O Supremo e o Processo Eleitoral. Belo Horizonte - MG: Letramento, 2019.

ARGUELHES, Diego Werneck; HARTMANN, Ivar A. Timing Control without Docket Control: How Individual Justices Shape the Brazilian Supreme Court's Agenda. Journal of Law and Courts, v. 5, n. 1, p. 105-140, 2017.

ARGUELHES, Diego Werneck; RECONDO, Felipe. Toffoli, Bolsonaro e o 'pacto': o problema da 'cooperação judicial antecipada'. Jota, 2019. Disponível em: <https://www.jota.info/stf/supra/stf-e-governo-o-fenomeno-da-cooperacaojudicial-antecipada-03062019>. Acesso em: 14 jul. 2019.

ARGUELHES, Diego Werneck; RIBEIRO, Leandro Molhano. Ministrocracia: o Supremo Tribunal individual e o processo democrático brasileiro. Novos Estudos - CEBRAP, v. 37, n. 1, p. 13-32, 2018.

BRASIL. Supremo Tribunal Federal. Notícias: Ministra Cármen Lúcia divulga relatório de primeiro ano de gestão à frente do STF. STF, 2017. Disponível em: <http://www.stf.jus.br/portal/cms/verNoticiaDetalhe.asp?idConteudo=357115>. Acesso em: 15 jul. 2019.

BRASIL. Supremo Tribunal Federal. Notícias: STF define pauta de julgamentos para o primeiro semestre de 2019. 2018. Disponível em:

<http://www.stf.jus.br/portal/cms/verNoticiaDetalhe.asp?idConteudo=398974\&cai 
xaBusca=N>. Acesso em: 6 jul. 2019.

BRÍGIDO, Carolina. Análise: Toffoli usa pauta do Supremo para acelerar debates no Congresso. O Globo, 2019. Disponível em:

$<$ https://oglobo.globo.com/brasil/analise-toffoli-usa-pauta-do-supremo-paraacelerar-debates-no-congresso-23699170>. Acesso em: 14 jul. 2019.

BRÍGIDO, Carolina. Toffoli e Marco Aurélio: dois ministros em pé de guerra. Época, 2019. Disponível em: <https://epoca.globo.com/toffoli-marco-aurelio-doisministros-em-pe-de-guerra-23577617>. Acesso em: 15 jul. 2019.

BRÍGIDO, Carolina. Toffoli ganha pontos com o governo ao adiar julgamento de drogas. Época, 2019. Disponível em: <https://epoca.globo.com/toffoli-ganhapontos-com-governo-ao-adiar-julgamento-de-drogas-23745301>. Acesso em: 6 jul. 2019.

CAMAROTTI, Gerson. Fora da agenda, Dilma tem encontro reservado com Lewandowski em Portugal. Blog do Camarotti - G1, 2015. Disponível em: $<$ http://g1.globo.com/politica/blog/blog-do-camarotti/post/fora-da-agenda-dilmatem-encontro-reservado-com-lewandowski-em-portugal.html>. Acesso em: 6 jul. 2019.

CAMPOS, João Pedroso de. Marco Aurélio diz que 'jamais' faria pacto entre Poderes, como Toffoli. Veja, 2019. Disponível em:

$<$ https://veja.abril.com.br/politica/marco-aurelio-diz-que-jamais-faria-pacto-entrepoderes-como-toffoli/>. Acesso em: 6 jul. 2019.

CANÁRIO, Pedro. Ainda hoje, julgo cada processo como se fosse o primeiro da minha vida. Consultor Juridico, 2015. Disponível em:

<https://www.conjur.com.br/2015-jun-12/entrevista-marco-aurelio-ministrosupremo-tribunal-federal>. Acesso em: 6 jul. 2019.

CARVALHO, Jailton de; SOUZA, André. Gilmar critica critérios para definir pauta e bate boca com Cármen Lúcia. O Globo, 2018. Disponível em: $<$ https://oglobo.globo.com/brasil/gilmar-critica-criterios-para-definir-pauta-bateboca-com-carmen-lucia-22512914>. Acesso em: 6 jul. 2019.

COELHO, Gabriela. Quero garantir que a "'lava jato'” vai continuar, defende Luiz Fux. Consultor Juridico, 2019. Disponível em: <https://www.conjur.com.br/2019- 
jul-08/quero-garantir-lava-jato-continuar-fux>. Acesso em: 15 jul. 2019.

COELHO, Gabriela. Toffoli suspende liminar que autorizava entrevista de Lula. Consultor Juridico, 2018. Disponível em: <https://www.conjur.com.br/2018-out01/toffoli-suspende-liminar-autorizava-entrevista-lula>. Acesso em: 6 jul. 2019.

COSTA, Emília Viotti da. O Supremo Tribunal Federal e a construção da cidadania. 2a ed. rev. São Paulo, SP: Editora Unesp, 2006.

D'AGOSTINO, Rosanne; BARBIÉRI, Luiz Felipe. STF começa julgamento sobre criminalização da homofobia. G1, 2019. Disponível em:

$<$ https://g1.globo.com/politica/noticia/2019/02/13/stf-julgamento-criminalizacaohomofobia.ghtml>. Acesso em: 6 jul. 2019.

DIMOULIS, Dimitri; LUNARDI, Soraya. Definição da pauta no Supremo Tribunal Federal e (auto) criação do processo objetivo. XVII Congresso Nacional do CONPEDI, v. 20, n. 21, p. 4357-4377, 2008.

DIMOULIS, Dimitri; LUNARDI, Soraya. O poder de quem define a pauta do STF. Folha de S. Paulo, 2012. Disponível em:

$<$ https://www1.folha.uol.com.br/fsp/opiniao/39484-o-poder-de-quem-define-apauta-do-stf.shtml>. Acesso em: 16 jul. 2019.

DINIZ, Laura. Decisão sobre Crusoé lança dúvidas sobre real motivação de inquérito no STF. Jota, 2019. Disponível em:

$<$ https://oglobo.globo.com/brasil/para-ministros-do-stf-juristas-inquerito-detoffoli-deve-ir-plenario-23611922>. Acesso em: 15 jul. 2019.

ESTEVES, Luiz Fernando Gomes. O que os números dizem sobre a pauta do STF de Cármen? In: FALCÃO, Joaquim; PEREIRA, Thomaz; ARGUELHES, Diego Werneck; et al (Orgs.). O Supremo Tribunal Criminal: o supremo em 2017. Belo Horizonte, MG: Letramento, 2018, p. 87-94.

ESTEVES, Luiz Fernando Gomes. Processo legislativo no Brasil. Belo Horizonte MG: Casa do Direito, 2018.

ESTEVES, Luiz Fernando Gomes. Votação secreta no Senado: uma questão apenas de transparência? In: FALCÃO, Joaquim; ARGUELHES, Diego Werneck; PEREIRA, Thomaz; et al (Orgs.). O Supremo e o Processo Eleitoral. Belo 
Horizonte - MG: Letramento, 2019, p. 197-203.

FALCÃO, Joaquim; ARGUELHES, Diego Werneck; RECONDO, Felipe (Orgs.). Onze supremos: o supremo em 2016. Belo Horizonte, MG: Letramento, 2017.

FALCÃO, Joaquim; OLIVEIRA, Fabiana Luci de. O STF e a agenda pública nacional: de outro desconhecido a supremo protagonista? Lua Nova: Revista de Cultura e Política, n. 88, p. 429-469, 2013.

FALCÃO, Márcio. Toffoli manda cumprir liminar de Fux que suspendeu entrevista de Lula. Jota, 2018. Disponível em: <https://www.jota.info/coberturasespeciais/liberdade-de-expressao/toffoli-manda-cumprir-liminar-de-fux-quesuspendeu-entrevista-de-lula-01102018>. Acesso em: 14 jul. 2019.

FONTAINHA, Fernando; SILVA, Angela Moreira Domingues da; NUÑEZ, Izabel Saenger. (Orgs.). História oral do Supremo: 1988-2013, v. 3: Sepúlveda Pertence.. Rio de Janeiro, RJ, Brasil: FGV Direito Rio, 2015.

FONTAINHA, Fernando; PAULA, Christiane Jalles de; SATO, Leonardo Seiichi Sasada; GUIMARÃES, Fabrícia Corrêa. (Orgs.). História oral do Supremo: 19882013, v. 9: Nelson Jobim. Rio de Janeiro, RJ, Brasil: FGV Direito Rio, 2015.

FREITAS, Hyndara. STF: Bolsonaro não pode, em decreto, extinguir conselhos criados por lei. Jota, 2019. Disponível em: <https://www.jota.info/stf/dosupremo/stf-bolsonaro-nao-pode-por-decreto-extinguir-conselhos-criados-lei13062019>. Acesso em: 6 jul. 2019.

GLEZER, Rubens; MACHADO, Eloísa. Presidência do STF derruba política contra escravidão moderna. Jota, 2015. Disponível em: <https://www.jota.info/opiniao-eanalise/artigos/presidencia-stf-derruba-politica-contra-escravidao-moderna14012015>. Acesso em: 16 jul. 2019.

GOMES NETO, José Mário Wanderley; LIMA, Flávia Danielle Santiago. Das 11 ilhas ao centro do arquipélago: os superpoderes do Presidente do STF durante o recesso judicial e férias. Revista Brasileira de Políticas Públicas, v. 8, n. 2, p. 741756, 2018.

GRILLO, Marco. Para ministros do STF e juristas, inquérito de Toffoli deve ir a plenário. O Globo, 2019. Disponível em: <https://oglobo.globo.com/brasil/para- 
ministros-do-stf-juristas-inquerito-de-toffoli-deve-ir-plenario-23611922>. Acesso em: 15 jul. 2019.

GULLINO, Daniel. Associação de juízes critica Toffoli por concordar com "pacto" que inclui reforma da Previdência. O Globo, 2019. Disponível em:

$<$ https://oglobo.globo.com/brasil/associacao-de-juizes-critica-toffoli-por-

concordar-com-pacto-que-inclui-reforma-da-previdencia-23702583>. Acesso em:

6 jul. 2019.

HARTMANN, Ivar Alberto Martins; FERREIRA, Lívia Da Silva. Ao relator, tudo: o impacto do aumento do poder do ministro relator no Supremo. Revista

Opinião Jurídica (Fortaleza), v. 13, n. 17, p. 268-283, 2016.

HILBINK, Lisa. Judges beyond politics in democracy and dictatorship: lessons

from Chile. New York: Cambridge University Press, 2007. (Cambridge studies in law and society).

JENNY, Marcelo; MÜLLER, Wolfgang. Presidents of Parliament: Neutral Chairmen or Assets of the Majority. In: DÖRING, Herbert (Org.). Parliaments and majority rule in western Europe. Frankfurt: New York: Campus ; St. Martin's Press, 1995, p. 326-364.

KINGDON, John W. Agendas, alternatives, and public policies. 2 ed. Harlow: Pearson, 2014. (Always learning).

LEFLAR, Robert A. The Multi-Judge Decisional Process. Maryland Law Review, v. 42, n. 4, p. 722-731, 1983.

LIMA, Frederico. Para Cármen Lúcia, legislação deve ser repressiva e dura contra corrupção. O Globo, 2018. Disponível em: <https://oglobo.globo.com/brasil/paracarmen-lucia-legislacao-deve-ser-repressiva-dura-contra-corrupcao-22705659>. Acesso em: 15 jul. 2019.

MAIA, Gustavo; SOARES, Jussara. Bolsonaro exalta Toffoli: “É muito bom nós termos aqui a Justiça ao nosso lado". O Globo, 2019. Disponível em: $<$ https://oglobo.globo.com/brasil/bolsonaro-exalta-toffoli-muito-bom-nos-termosaqui-justica-ao-nosso-lado-23706320>. Acesso em: 15 jul. 2019. 
MENDES, Conrado Hübner. Constitutional courts and deliberative democracy. Oxford New York: Oxford University Press, 2015.

MENDES, Conrado Hübner. Direitos Fundamentais, Separação de Poderes e Deliberação. São Paulo: Saraiva, 2011.

MENDES, Conrado Hübner. O Projeto de uma Corte Deliberativa. In: VOJVODIC, Adriana; PINTO, Henrique Motta; GORZONI, Paula; et al (Orgs.). Jurisdição constitucional no Brasil. São Paulo, SP: Sociedade Brasileira de Direito PúblicoSBDP : Malheiros Editores : Fundação Getulio Vargas, Direito GV, 2012, p. 53-74.

MENDES, Conrado Hübner. Pode o juiz falar? Época, 2018. Disponível em: $<$ https://epoca.globo.com/conrado-hubner-mendes/pode-juiz-falar-23004472>. Acesso em: 6 jul. 2019.

NUNES, Daniel Capecchi; ESTEVES, Luiz Fernando Gomes. “Judiciarismo de Coalizão"e a crise do governo Bolsonaro. Jota, 2019. Disponível em: < https://www.jota.info/stf/supra/judiciarismo-de-coalizao-e-a-crise-do-governobolsonaro-29052019>. Acesso em 06 jul. 2019.

OLIVEIRA, Mariana; D’AGOSTINO, Rosanne. Toffoli derruba decisão de Marco Aurélio, e eleição no Senado será secreta. G1, 2019. Disponível em: <https:/g1.globo.com/politica/noticia/2019/01/09/toffoli-derruba-decisao-demarco-aurelio-e-eleicao-no-senado-sera-secreta.ghtml>. Acesso em: 6 jul. 2019.

PEREIRA, Thomaz. A tragédia no STF. Folha de S. Paulo, 2017. Disponível em: < https://www1.folha.uol.com.br/opiniao/2017/09/1919967-a-tragedia-no-stf.shtml>. Acesso em: 6 jul. 2019.

PEREIRA, Thomaz; ARGUELHES, Diego Werneck. Uma indicação terrível? Jota, 2019. Disponível em: <https://www.jota.info/stf/supra/uma-indicacao-terrivel12072019>. Acesso em: 15 jul. 2019.

PESSOA, Gabriela Sá. Toffoli diz que hoje prefere chamar golpe militar de 'movimento de 1964. Folha de S. Paulo, 2018. Disponível em: <https://www1.folha.uol.com.br/poder/2018/10/toffoli-diz-que-hoje-preferechamar-ditadura-militar-de-movimento-de-1964.shtml>. Acesso em: 14 jul. 2019.

RECONDO, Felipe. O senso de oportunidade de Cármen Lúcia. Jota, 2018. 
Disponível em: <https://www.jota.info/stf/do-supremo/carmen-lucia-sensooportunidade-16072018>. Acesso em: 14 jul. 2019.

RECONDO, Felipe; WEBER, Luiz. Os Onze: O STF, seus bastidores e suas crises. São Paulo: Companhia das Letras, 2019.

RESENDE, Ranieri Lima; VIEIRA, José Ribas. The Agenda-Setting Crisis in the Brazilian Supreme Court. Int'1 J. Const. L. Blog, 2018. Disponível em:

$<$ http://www.iconnectblog.com/2018/04/the-agenda-setting-crisis-in-the-braziliansupreme-court/>. Acesso em: 16 jul. 2019.

RESENDE, Thiago. Toffoli derruba decisão que afetava venda de ativos da Petrobras. Folha de S. Paulo, 2019. Disponível em:

<https://www1.folha.uol.com.br/mercado/2019/01/toffoli-derruba-decisao-queafetava-venda-de-ativos-da-petrobras.shtml>. Acesso em: 6 jul. 2019.

REZENDE, Constança. Crítica por STF “pactar" com Bolsonaro não representa todos juízes, diz AMB. UOL, 2019. Disponível em:

$<$ https://noticias.uol.com.br/politica/ultimas-noticias/2019/05/29/critica-a-pactodo-stf-com-bolsonaro-nao-representa-todos-juizes-diz-amb.htm>. Acesso em: 6 jul. 2019.

ROSA, Vera. Toffoli diz que "pacto" marcará novo tempo' na relação entre os Poderes no País. O Estado de S. Paulo, 2019. Disponível em: $<$ https://politica.estadao.com.br/noticias/geral,toffoli-diz-que-pacto-marcaranovo-tempo-na-relacao-entre-os-poderes-no-pais,70002846741>. Acesso em: 8 jul. 2019.

SEM AUTOR. "Jair Bolsonaro toma posse como presidente da República e promete pacto nacional". Jornal Nacional, 2019 (2019a). Disponível em: <https:/g1.globo.com/jornal-nacional/noticia/2019/01/01/jair-bolsonaro-tomaposse-como-presidente-da-republica-e-promete-pacto-nacional.ghtml $>$. Acesso em: 14 jul. 2019.

SEM AUTOR. "Marco Aurélio critica "manipulação da pauta" no STF: 'tempos estranhos"'. O Globo, 2018. Disponível em:

$<$ https://oglobo.globo.com/brasil/marco-aurelio-critica-manipulacao-da-pauta-nostf-tempos-estranhos-22827300>. Acesso em: 6 jul. 2019. 
SEM AUTOR. "Toffoli suspende liminar de Marco Aurélio a favor de soltar condenados em 2a instância". Folha de S. Paulo, 2019 (2019b). Disponível em: $<$ https://www1.folha.uol.com.br/poder/2018/12/toffoli-suspende-liminar-demarco-aurelio-a-favor-de-soltar-condenados-em-segunda-instancia.shtml>. Acesso em: 6 jul. 2019.

SILVA, Virgílio Afonso da. De Quem Divergem os Divergentes: os Votos Vencidos no Supremo Tribunal Federal. Direito, Estado e Sociedade, n. 47, p. 205-225, 2015.

SILVA, Virgílio Afonso da. Deciding without deliberating. International Journal of Constitutional Law, v. 11, n. 3, p. 557-584, 2013.

SILVA, Virgílio Afonso da. "Um voto qualquer"? O papel do ministro relator na deliberação no Supremo Tribunal Federal. REI - REVISTA ESTUDOS

INSTITUCIONAIS, v. 1, n. 1, p. 180-200, 2016.

TEIXEIRA, Matheus. STF bate recorde de monocráticas em ações constitucionais em 2018. Jota, 2019. Disponível em: <https://www.jota.info/stf/do-supremo/stfrecorde-monocraticas-acoes-constitucionais-2018-15012019>. Acesso em:

6 jul. 2019.

VALENTE, Rubens. Mensalão - o julgamento: Atrasos equivalem a mais de duas sessões. Folha de S. Paulo, Disponível em:

$<$ https://www1.folha.uol.com.br/fsp/poder/65160-atrasos-equivalem-a-mais-deduas-sessoes.shtml>. Acesso em: 6 jul. 2019.

VERISSIMO, Marcos Paulo. A constituição de 1988, vinte anos depois: suprema corte e ativismo judicial "à brasileira”. Revista Direito GV, v. 4, n. 2, p. 407-440, 2008.

VIEIRA, Oscar Vilhena. Supremocracia. Revista Direito GV, v. 4, n. 2, p. 441-463, 2008.

VOJVODIC, Adriana de Moraes; MACHADO, Ana Mara França; CARDOSO, Evorah Lusci Costa. Escrevendo um romance, primeiro capítulo: precedentes e processo decisório no STF. Revista Direito GV, v. 5, n. 1, p. 21-44, 2009. 